\title{
Disconnect in Assessments of Autosomal Dominant Polycystic Kidney Disease Burden Between Patients and Physicians: A Survey Study
}

This article was published in the following Dove Press journal: International Journal of Nephrology and Renovascular Disease

\author{
Myrlene Sanon Aigbogun' \\ Dorothee Oberdhan (D)' \\ Michael J Doane ${ }^{2}$ \\ Jillian Rooney ${ }^{2}$ \\ Brian C Inyart ${ }^{2}$ \\ Christina S Pao $\mathbb{D D}^{1}$ \\ Alexis H Denny ${ }^{3}$ \\ 'Health Outcomes, Otsuka \\ Pharmaceutical Development \& \\ Commercialization, Inc., Princeton, NJ, \\ USA; ${ }^{2}$ Health Outcomes Research, \\ New York, NY, USA; ${ }^{3}$ Government \\ Affairs, Polycystic Kidney Disease (PKD) \\ Foundation, Kansas City, MO, USA
}

Background: Autosomal dominant polycystic kidney disease (ADPKD) is a rare inherited kidney disorder with considerable symptom burden and negative effects even in early-stage disease. Patients' reporting of ADPKD symptom burden may differ from physicians' impressions. In this quantitative, cross-section survey study, we evaluated patient and physician assessments of symptom burden at early- and late-stage ADPKD.

Methods: In the United States, 300 patients with ADPKD and 155 physicians treating patients with ADPKD completed online surveys administered by Kantar. Disease stage was categorized as early (chronic kidney disease [CKD] stages 1-3) or late (stages 4-5). Patients completed the Work Productivity and Activity Impairment Questionnaire and reported current disease symptoms. Patients and physicians assessed impacts of ADPKD on daily life and burden of specific symptoms. Statistical analyses compared patient versus physician responses stratified by early- versus late-stage ADPKD.

Results: We found that impairment in work productivity was statistically greater in late- versus early-stage CKD. Compared with physicians' impressions, patients were more likely at early stages and less likely at later stages to report a moderate/strong impact of ADPKD on daily life. Among patients, $74 \%$ with early- and $88 \%$ with late-stage disease reported that ADPKD caused them to modify their daily lives. In early-stage disease, patients reported a statistically greater burden from feeling exhausted and less burden from dull kidney pain, cardiovascular problems, high blood pressure, and liver cysts than physicians assumed. At later stages, patients reported feeling exhausted and skeletal/joint pain as more burdensome, and frequent urination, high blood pressure, liver cysts, and hematuria as less burdensome, compared with physicians' impressions. Conclusion: The results of this survey study demonstrate a disconnect between patients' experiences and physicians' awareness of the burden of ADPKD and highlight the need for more patient/physician discussion of symptoms and disease management.

Keywords: autosomal dominant polycystic kidney disease, ADPKD, symptom burden, patient reports, physician views, survey

\section{Introduction}

Autosomal dominant polycystic kidney disease (ADPKD) is a rare, inherited (monogenic) kidney disorder affecting approximately 4 in 10,000 individuals in the United States and Europe. ${ }^{1-3}$ ADPKD is the fourth-leading cause of end-stage renal disease, and more than half of patients with ADPKD develop kidney failure by age $60 .{ }^{4}$

The progression of ADPKD is characterized by the growth of cysts and consequent enlargement of the kidneys. ${ }^{5}$ The disease is associated with considerable
Correspondence: Dorothee Oberdhan Health Outcomes, Otsuka Pharmaceutica Development \& Commercialization, Inc., 2440 Research Boulevard, Rockville, MD 20850, USA

Tel $+\mid 240-683-3517$

$\mathrm{Fax}+|30|-72 \mid-7517$

Email dorothee.oberdhan@otsuka-us.com
International Journal of Nephrology and Renovascular Disease 202I:14 105-II5 
symptom burden, including flank and abdominal pain, urinary tract and cyst infections, kidney stones, hematuria, hypertension, and, indirectly, an increased risk of cardiovascular events, intracranial aneurysms, and mortality. 4,6,7 Severity of chronic kidney disease (CKD) is commonly classified as stage 1 (glomerular filtration rate [GFR] $\geq 90 \mathrm{~mL} / \mathrm{min} / 1.73 \mathrm{~m}^{2}$; structural or urinary anomalies) to stage 5 (GFR $<15 \mathrm{~mL} / \mathrm{min} / 1.73 \mathrm{~m}^{2}$; kidney failure, including those receiving kidney replacement therapy). ${ }^{8,9}$

Multiple studies have demonstrated substantial decline in quality of life among patients with $\mathrm{ADPKD}^{10-12}$ and have found that physical symptoms and quality of life worsen as ADPKD progresses. ${ }^{7,13,14}$ Although the burden of ADPKD may be more evident at later disease stages, considerable negative physical and emotional impacts have been observed even in patients with early-stage disease. ${ }^{7,13,15}$ In one study in 9 European countries, $88 \%$ of patients with ADPKD at CKD stages ${ }^{8} 1$ or 2 reported experiencing symptoms including pain, fatigue, and weakness. ${ }^{15}$ In another study in 4 Scandinavian countries, $48 \%$ of patients with ADPKD at CKD stages 1-3 experienced pain or discomfort, and $30 \%$ experienced anxiety or depression. ${ }^{13}$ Pain and other symptoms occurring early in the course of ADPKD can be significant enough to adversely affect work and daily activities, including walking and sleep. ${ }^{7,15}$

Some previous research has suggested that patients with ADPKD and the physicians treating them may view the symptom burden of ADPKD differently. ${ }^{15,16}$ However, studies on this topic have been qualitative in nature or evaluated only limited dimensions of the overall disease burden in ADPKD.

The primary objective of this quantitative survey study was to evaluate patient and physician assessments of the symptom burden in ADPKD for patients with CKD stages $1-5$ in the United States. Secondary objectives were to evaluate differences in the assessment of ADPKD symptom burden across patient subgroups (by CKD stage) and between patients and physicians and to assess the relationship between disease symptoms, work productivity, and daily activities.

\section{Materials and Methods}

This study was approved by the Pearl Pathways Institutional Review Board and was conducted in accordance with the Declaration of Helsinki.

\section{Study Design}

This was a cross-sectional online survey study. During a survey design phase in July 2018, an initial clinician survey and patient survey were developed. Cognitive debriefing telephone interviews were conducted with a group of 8 patients with ADPKD and 8 nephrologists who treat ADPKD to review the survey instrument, ensure comprehension, and refine survey questions where needed. Details of the survey instrument validation process are provided in the Appendix.

In the present quantitative study phase, a 30-minute online survey of 300 patients (with a target of 60 patients per CKD stage) and 155 physicians was conducted by Kantar from September 5, 2018, through September 21, 2018.

\section{Patients}

Patients with ADPKD living in the United States were recruited via e-mail messages sent to members of the PKD Foundation. Patients were included if they provided informed consent, self-reported a diagnosis of ADPKD, self-reported their CKD stage (ie, 1-5), ${ }^{8}$ were able to read and understand English, and had e-mail/internet access.

\section{Physicians}

Physician respondents were members of the Lightspeed Panel in the United States. Lightspeed Panel members are recruited through opt-in e-mails, coregistration with panel partners, e-newsletter campaigns, and online banner placements. Physicians were included if they provided informed consent; were board-certified or -eligible in nephrology; had been in practice between 2 and 30 years; treated $\geq 150$ patients per month; treated $\geq 3$ patients with ADPKD per year; practiced in a community setting, center of excellence, or dialysis clinic; spent $\geq 75 \%$ of their time in clinical practice; were able to read and understand English; and had e-mail/internet access.

\section{Measures}

Patients provided information about their demographic characteristics, disease characteristics, and comorbidities. Physicians provided information about their demographic characteristics, medical practices, and characteristics of their patients with ADPKD.

The Work Productivity and Activity Impairment Questionnaire $^{17}$ was administered to patients to assess the impact of health problems on work productivity. Work productivity measures were administered only to patients who were employed, and the activity impairment item was asked of all patients. 
Impact of ADPKD on daily life was measured among patients and physicians on a 5-point Likert scale with the following response options: 1 (no impact), 2 (slight impact), 3 (moderate impact), 4 (strong impact), and 5 (very strong impact).

Patients reported current PKD-related physical and emotional symptoms. Patients and physicians reported their assessments of symptom burden across a series of CKD-related symptoms. This measure of symptoms included a range of disease manifestations, including signs and diagnosed complications. Symptom burden was assessed on a Likert scale ranging from 1 (least burdensome) to 5 (most burdensome). For patients, symptom burden was measured by self-reported experience and burden. Only patients reporting they experienced a specific symptom rated the burden of that symptom. For physicians, symptom burden was measured by their understanding of their early- and late-stage patients' experience and burden of symptoms. Certain symptoms were assessed by patients and not by clinicians, because of the subjective and intrinsic nature of those symptoms.

\section{Statistical Methods}

Means and standard deviations (SDs) were used to describe continuous variables, while percentages and frequencies were used to describe categorical variables. For patients, descriptive statistics were calculated by early (CKD stages 1-3) versus late (CKD stages 4-5) stage of disease. For physicians, descriptive statistics were calculated for their patients with early- versus late-stage ADPKD.

To test for significant differences on study measures by early versus late CKD stage, independent samples $t$ tests and chi-square $\left(\chi^{2}\right)$ tests were carried out separately for the patient and physician study populations, depending on the nature of the dependent variables.

To evaluate differences in patient reports and physician impressions of symptom burden in ADPKD, generalized linear models with identity link functions were used to estimate mean ratings of the level of symptom burden, adjusting for age and sex for all groups and in all models. Pairwise comparisons of adjusted means were estimated between physicians and patients to identify statistically significant differences in assessments of ADPKD symptom burden.

To conduct sensitivity analyses by patient CKD stage, statistical power analyses indicated that a sample size of 60 patients per CKD stage would provide $78 \%$ power to detect medium effect sizes (Cohen's $d=0.5$ ) across the CKD stage subgroups. Therefore, a recruitment target of 60 patients per CKD stage was established.

Data management and statistical analyses were performed in SPSS version 23 (SPSS Inc., IBM Corp.). An alpha level of 5\% (two-sided) was used for all null hypothesis testing.

\section{Results}

\section{Patient Characteristics}

Overall, 300 patients were included in the sample, with $n=60$ at each CKD stage (1 to 5). Age varied widely, with an overall mean age of $52.1(\mathrm{SD}=12.8)$ years (Table 1$)$. Most patients

Table I Patient Demographic Characteristics by Early or Late CKD Stage

\begin{tabular}{|c|c|c|c|}
\hline Characteristics & $\begin{array}{c}\text { Early } \\
\text { CKD Stage } \\
(1-3) \\
(n=180)\end{array}$ & $\begin{array}{c}\text { Late } \\
\text { CKD Stage } \\
(4-5) \\
(n=120)\end{array}$ & $P$ value \\
\hline Age, mean (SD), y & $47.3(12.5)$ & $59.3(9.5)$ & $<0.001$ \\
\hline $\begin{array}{l}\text { Age, y } \\
\begin{array}{l}18-24 \\
25-34 \\
35-44 \\
45-54 \\
55-64 \\
65+\end{array}\end{array}$ & $\begin{array}{c}5(2.8) \\
30(16.7) \\
47(26.1) \\
39(21.7) \\
42(23.3) \\
17(9.4)\end{array}$ & $\begin{array}{c}0 \\
1(0.8) \\
8(6.7) \\
27(22.5) \\
49(40.8) \\
35(29.2)\end{array}$ & $<0.001$ \\
\hline Female & $125(69.4)$ & $83(69.2)$ & 0.96 \\
\hline $\begin{array}{l}\text { Ethnicity/race }^{\mathrm{a}} \\
\text { White } \\
\text { Hispanic } \\
\text { African American/black } \\
\text { Asian/Pacific Islander } \\
\text { Native American/Alaskan Native } \\
\text { Other } \\
\text { Unknown }\end{array}$ & $\begin{array}{c}162(90.0) \\
5(2.8) \\
4(2.2) \\
3(1.7) \\
0 \\
5(2.8) \\
1(0.6)\end{array}$ & $\begin{array}{c}110(91.7) \\
7(5.8) \\
3(2.5) \\
0 \\
1(0.8) \\
3(2.5) \\
0\end{array}$ & $\begin{array}{l}0.63 \\
0.19 \\
0.88 \\
0.16 \\
0.22 \\
0.88 \\
0.41\end{array}$ \\
\hline Currently employed & $135(75.0)$ & $56(46.7)$ & $<0.001$ \\
\hline $\begin{array}{l}\text { Annual household income } \\
<\$ 50,000 \\
\$ 50,000-\$ 99,999 \\
\$ 100,000-\$ 149,000 \\
\geq \$ 150,000 \\
\text { Declined to answer }\end{array}$ & $\begin{array}{c}29(16.1) \\
60(33.3) \\
43(23.9) \\
31(17.2) \\
17(9.4)\end{array}$ & $\begin{array}{l}29(24.2) \\
35(29.2) \\
19(15.8) \\
24(20.0) \\
13(10.8)\end{array}$ & 0.24 \\
\hline Have health insurance & $175(97.2)$ & $120(100.0)$ & 0.18 \\
\hline $\begin{array}{l}\text { Education } \\
\text { Less than college degree } \\
\text { College degree or higher }\end{array}$ & $\begin{array}{c}56(31.1) \\
124(68.9)\end{array}$ & $\begin{array}{l}40(33.3) \\
80(66.7)\end{array}$ & 0.69 \\
\hline
\end{tabular}

Notes: Except for age, all values are displayed as $\mathrm{n}(\%) .{ }^{\text {a }}$ Multiple responses were possible.

Abbreviations: CKD, chronic kidney disease; SD, standard deviation. 
were female (69\%), non-Hispanic white $(90 \%)$, employed (64\%), had health insurance (98\%), and had a college degree (68\%). Among all patients, $69 \%$ had commercial/private health insurance, 26\% had Medicare, and 5\% had Medicaid coverage. Typical of ADPKD progression, patients at earlier CKD stages (1-3) were generally younger than patients at later stages (Table 1).

Patients at later CKD stages (4-5) had lived longer with ADPKD since diagnosis, were more likely to be receiving dialysis, and were more likely to be on a kidney transplant list (Table 2). Most patients (87\% overall) had comorbid conditions, most commonly hypertension, urinary tract infections, kidney stones, and depression. No statistically significant differences were noted in number or type of comorbidities between patients with early versus late CKD stage. Overall, $96 \%$ of patients were currently seeing a nephrologist or kidney specialist and $53 \%$ were seeing a primary care practitioner (Table 2).

\section{Physician Characteristics}

Of 155 responding physicians, $79 \%$ were male and $91 \%$ were 35 to 64 years of age. All were nephrologists, $99 \%$ were boardcertified, $88 \%$ were in a group practice, $46 \%$ were associated with a university or hospital, and $21 \%$ were transplant nephrologists. Regarding physicians' location by region of the US, $20 \%$ were in the Northeast, $22 \%$ in the Midwest, $37 \%$ in the South, and $21 \%$ in the West. Physicians had spent a mean of $15.5(\mathrm{SD}=6.7)$ years in practice, and they spent a mean of $95 \%$ $(\mathrm{SD}=6 \%)$ of their time in direct patient care. Among the responding physicians, $47 \%$ practiced in a suburban setting, $46 \%$ in an urban setting, and $7 \%$ in a rural setting.

Physicians' mean ADPKD patient load per year was $76.9(\mathrm{SD}=131.9)$ patients, representing a mean of $9.7 \%$ $(\mathrm{SD}=20.0)$ of physicians' patient load per year. Physicians estimated a mean of $57 \%(\mathrm{SD}=18)$ of their patients with ADPKD had early-stage (1-3) disease, and $43 \%(\mathrm{SD}=18)$ had late-stage $(4-5)$ disease.

\section{Impact on Work Productivity}

Three-quarters of early-stage patients were employed, compared with slightly less than half of patients with latestage disease (Table 1). Impairments in work productivity and daily activities were substantial at both early and late stages of the disease, with statistically greater impairment in the later disease stages (Figure 1). These findings do not distinguish between patients with full-time versus parttime positions.

\section{Impact on Daily Life}

At CKD stages 1 and 2, patients were more likely to report that ADPKD had a moderate, strong, or very strong impact on their daily life compared with physicians' impressions of ADPKD's impact (Figure 2; statistical comparisons were not performed). In contrast, at CKD stages 3 to 5, physicians were more likely to assume a moderate, strong, or very strong impact of the disease, compared with patients' own reporting. Among patients, 74\% with earlystage (1-3) and $88 \%$ with late-stage (4-5) disease reported that ADPKD had caused them to modify their daily lives (data not shown).

\section{Current Symptoms}

Patients reported experiencing a mean of $7.1(\mathrm{SD}=4.7)$ current PKD-related symptoms. Late-stage CKD patients experienced a mean of $8.0(\mathrm{SD}=4.9)$ symptoms, significantly more than early-stage patients' $(6.4$ [SD $=4.5]$ symptoms; $P<0.01$ ).

Common physical and emotional symptoms included high blood pressure (reported by $64 \%$ of all patients), feeling exhausted or experiencing fatigue/tiredness (52\%), feeling guilt about the disease's impact on family members (45\%), dull kidney pain (42\%), bruising easily (41\%), body image issues (40\%), fullness/bloating (39\%), frequent urination (39\%), and problems sleeping (38\%, Figure 3). A number of symptoms, including feeling exhausted, occurred more often (with statistically significant differences) among patients with late- versus earlystage disease (Figure 3).

\section{Patient versus Physician Assessments of Symptom Burden}

Among patients with early-stage disease, the most burdensome symptoms of their ADPKD were feeling exhausted or fatigue/tiredness, shortness of breath, sharp kidney pain, and cyst rupture (Figure 4). These patients reported a significantly greater burden of feeling exhausted compared with the burden of feeling exhausted assumed by physicians (Figure 4). On the other hand, physicians believed several symptoms (dull kidney pain, cardiovascular problems, high blood pressure, and liver cysts) were significantly more burdensome in early disease stages than patients reported.

For patients with late-stage CKD, the most burdensome symptoms were feeling exhausted or experiencing fatigue/tiredness, cyst rupture, sharp kidney pain, 
Table 2 Patient Disease Characteristics by Early or Late CKD Stage

\begin{tabular}{|c|c|c|c|}
\hline Characteristics, n (\%) & $\begin{array}{l}\text { Early CKD Stage }(1-3) \\
\qquad n=180\end{array}$ & $\begin{array}{l}\text { Late CKD Stage (4-5) } \\
\qquad n=120\end{array}$ & $P$ value \\
\hline Months since diagnosis, mean (SD) & $183.2(|2| .8)$ & $301.8(149.0)$ & $<0.001$ \\
\hline $\begin{array}{l}\text { Provider type that made ADPKD diagnosis } \\
\text { Nephrologist/kidney specialist } \\
\text { Primary care } \\
\text { Emergency department } \\
\text { Obstetrician/gynecologist } \\
\text { Radiologist } \\
\text { Other } \\
\text { Unknown }\end{array}$ & $\begin{array}{l}45(25.0) \\
67(37.2) \\
13(7.2) \\
10(5.6) \\
24(13.3) \\
19(10.6) \\
2(1.1)\end{array}$ & $\begin{aligned} 22 & (18.3) \\
61 & (50.8) \\
7 & (5.8) \\
7 & (5.8) \\
8 & (6.7) \\
14 & (11.7) \\
1 & (0.8)\end{aligned}$ & 0.24 \\
\hline $\begin{array}{l}\text { Provider type currently seeing } \\
\text { Nephrologist/kidney specialist } \\
\text { Primary care } \\
\text { Other }\end{array}$ & $\begin{array}{l}168(93.3) \\
96(53.3) \\
21(11.7)\end{array}$ & $\begin{array}{c}\text { I } 20(100.0) \\
64(53.3) \\
28(23.3)\end{array}$ & $\begin{array}{c}0.004 \\
1.00 \\
0.007\end{array}$ \\
\hline $\begin{array}{l}\text { Duration of symptoms before formal diagnosis, y } \\
<1 \\
I-2 \\
\geq 3 \\
\text { Do not recall }\end{array}$ & $\begin{array}{l}85(47.2) \\
19(10.6) \\
20(11.1) \\
56(31.1)\end{array}$ & $\begin{array}{l}56(46.7) \\
12(10.0) \\
23(19.2) \\
29(24.2)\end{array}$ & 0.19 \\
\hline $\begin{array}{l}\text { Biological family members with ADPKD diagnosis } \\
0 \\
1 \\
2 \\
3 \\
4 \\
\geq 5\end{array}$ & $\begin{array}{c}0 \\
58(32.2) \\
52(28.9) \\
33(18.3) \\
17(9.4) \\
20(11.1)\end{array}$ & $\begin{array}{c}0 \\
28(23.3) \\
22(18.3) \\
24(20.0) \\
21(17.5) \\
25(20.8)\end{array}$ & 0.01 \\
\hline On dialysis & $\mathrm{I}(0.6)$ & $12(10.0)$ & $<0.001$ \\
\hline On kidney transplant list & $3(1.7)$ & $33(27.5)$ & $<0.001$ \\
\hline Charlson Comorbidity Index score, mean (SD) & $0.21(0.59)$ & $0.35(0.84)$ & 0.08 \\
\hline $\begin{array}{l}\text { Comorbidities } \\
\qquad \begin{array}{l}0 \\
1 \\
\geq 2\end{array}\end{array}$ & $\begin{array}{l}27(15.0) \\
54(30.0) \\
99(55.0)\end{array}$ & $\begin{array}{l}12(10.0) \\
47(39.2) \\
61(50.8)\end{array}$ & 0.81 \\
\hline $\begin{array}{l}\text { Comorbid condition } \\
\text { Hypertension } \\
\text { Urinary tract infections } \\
\text { Kidney stones } \\
\text { Depression } \\
\text { Diabetes without chronic complications } \\
\text { Rheumatologic disease } \\
\text { Any tumor } \\
\text { Chronic pulmonary disease } \\
\text { Diabetes with chronic complications }\end{array}$ & $\begin{array}{l}129(71.7) \\
50(27.8) \\
38(21.1) \\
27(15.0) \\
8(4.4) \\
9(5.0) \\
5(2.8) \\
3(1.7) \\
2(1.1)\end{array}$ & $\begin{array}{l}90(75.0) \\
39(32.5) \\
18(15.0) \\
21(17.5) \\
12(10.0) \\
9(7.5) \\
3(2.5) \\
2(1.7) \\
1(0.8)\end{array}$ & $\begin{array}{l}0.52 \\
0.38 \\
0.18 \\
0.56 \\
0.06 \\
0.37 \\
0.88 \\
1.00 \\
0.81\end{array}$ \\
\hline
\end{tabular}

Note: Except for months since diagnosis and Charlson Comorbidity Index score, all values are displayed as $\mathrm{n}(\%)$.

Abbreviations: ADPKD, autosomal dominant polycystic kidney disease; CKD, chronic kidney disease; SD, standard deviation. 


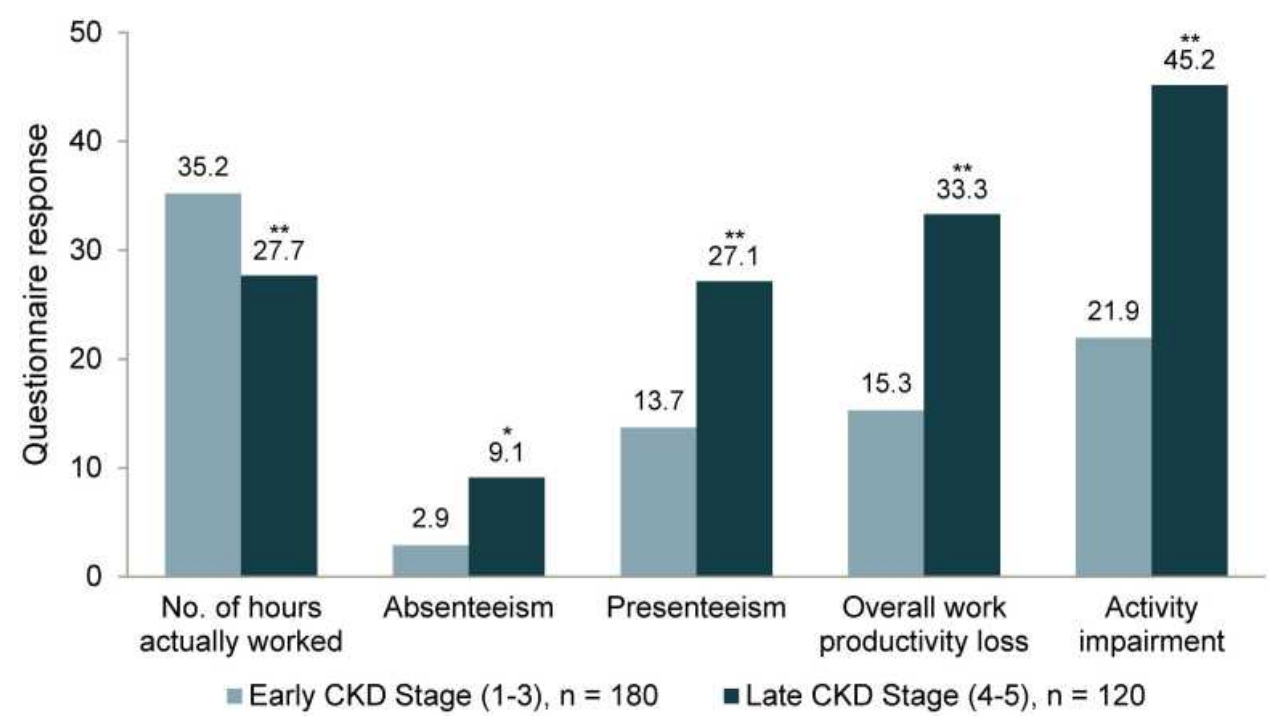

Figure I Patients' report of work productivity and activity impairment by CKD stage in ADPKD. Except for number of hours actually worked in the past week, scores represent percentages. Except for activity impairment, responses were based on employed patients only $(n=135$ patients at stages $I-3 ; n=56$ patients at stages $4-5)$. $* P<$ $0.05 ; * * P<0.01$ versus early stage.

Abbreviations: ADPKD, autosomal dominant polycystic kidney disease; CKD, chronic kidney disease.

and skeletal/joint pain (Figure 5), and the reported burden of these symptoms was higher than that reported by early-stage patients (Figure 4). Physicians significantly underestimated the burden of feeling exhausted and skeletal/joint pain relative to late-stage patients' reports (Figure 5). However, physicians assumed several other symptoms to be significantly more burdensome compared with patients' own reporting: frequent urination, high blood pressure, liver cysts, and hematuria.
In addition to symptoms for which burden was assessed by both patients and physicians, patients assessed the burden associated with these 8 additional issues: unable to complete a full day's work at job or home (mean burden $=4.7$ at stages $1-3$; mean burden $=4.3$ at stages $4-5)$, unable to engage in leisure activities (4.3; $3.8)$, problems sleeping $(3.7 ; 4.0)$, feeling guilty about PKD's impact on children or other family members (3.5; $3.8)$, body image issues $(3.4 ; 3.8)$, feeling anxious about PKD and prognosis $(3.3 ; 3.8)$, feeling discomfort or pain

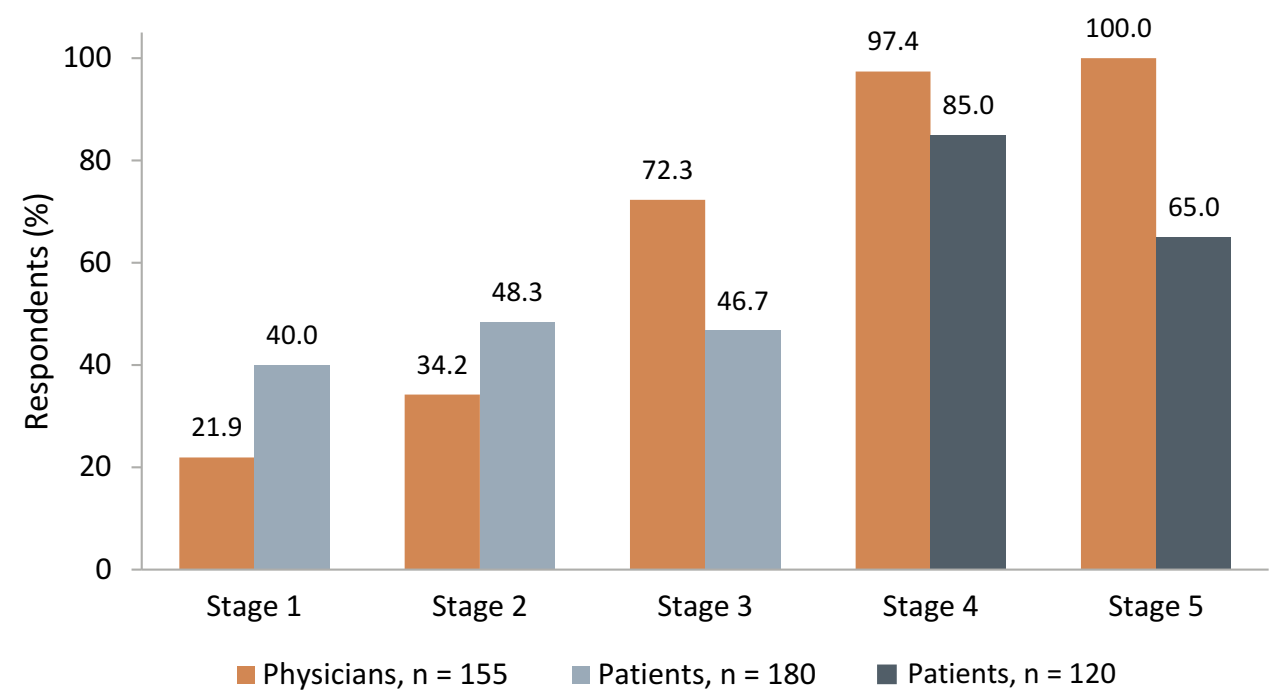

Figure 2 Proportion of physicians and patients stating that ADPKD has a moderate, strong, or very strong impact on patient's daily life at each CKD stage. Abbreviations: ADPKD, autosomal dominant polycystic kidney disease; CKD, chronic kidney disease. 


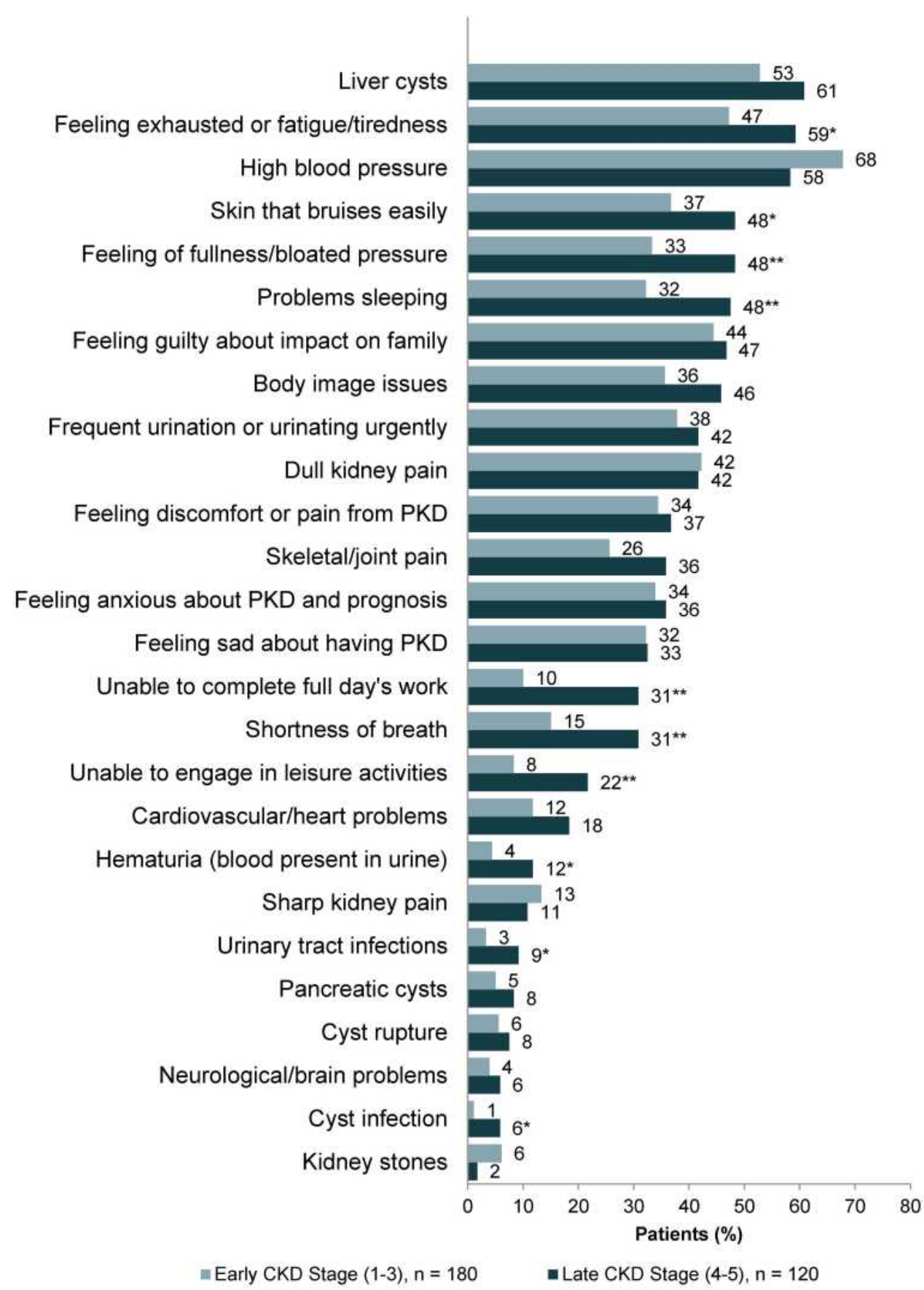

Figure 3 Proportion of patients reporting current physical and emotional symptoms by CKD stage in ADPKD, ordered by symptom prevalence during late-stage disease. $P$ values were calculated using $\chi^{2}$ tests. $* P<0.05$, $* * P<0.01$ vs early stage.

Abbreviations: ADPKD, autosomal dominant PKD; CKD, chronic kidney disease; PKD, polycystic kidney disease.

from PKD $(3.4 ; 3.6)$, and feeling sad about having PKD $(3.2 ; 3.4)$.

\section{Discussion}

This study is one of few to assess both patients' reporting and physicians' impressions of the burden of symptoms in ADPKD,$^{15}$ and, to our knowledge, the only such study among patients in the US. In this large survey study (300 patients and 155 physicians), even patients with earlystage CKD reported burdensome symptoms, including exhaustion, shortness of breath, and sharp kidney pain. Consistent with previous studies, later CKD stages were associated with increased symptom prevalence and burden compared with earlier stages. ${ }^{7,13,14}$

This study also demonstrated substantial impairment in work productivity and daily activities at all stages of the 


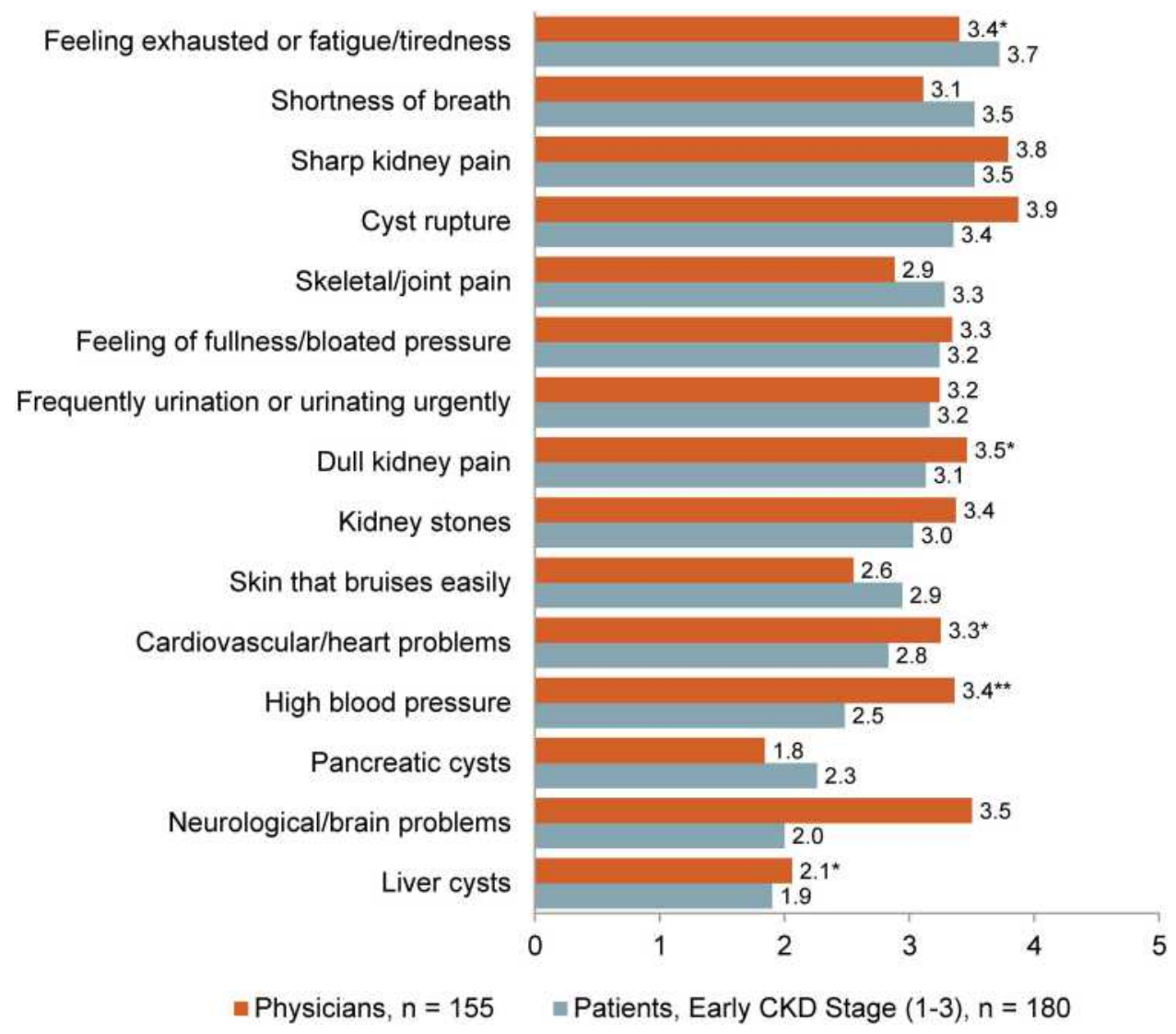

Figure 4 Early-stage (CKD stage I-3) patients' versus physicians' assessments of symptom burden in ADPKD, ordered by patients' ratings of burden. Severity scale: I (least burdensome) to 5 (most burdensome). Only patients reporting they experienced a specific symptom rated the burden of that symptom. Of I55 physicians enrolled in the study, 147 remained after removing physicians with unknown/missing age and/or sex values. $P$ values were calculated using pairwise comparisons of age- and sex-adjusted estimated means. $* P<0.05, * * P<0.01$ versus patients.

Abbreviations: ADPKD, autosomal dominant polycystic kidney disease; CKD, chronic kidney disease.

disease. A higher proportion of patients with early- versus late-stage CKD were employed, which may reflect the effects of advancing disease as well as the older average age of later-stage patients. Later-stage ADPKD had the greatest impact on work productivity and activity levels, consistent with the progressive nature of the disease and impact on patients' health.

A substantial discrepancy was observed between physicians' assumptions and patients' reporting of the impact of ADPKD on daily life. Physicians underestimated the impact of the earliest stages of disease (1 and 2) relative to patients' own reports, and physicians overestimated the impact of the later disease stages. Almost three-quarters (74\%) of patients with stage 1-3 disease and $88 \%$ of patients with stage 4-5 disease reported that ADPKD had caused them to modify their daily lives, a testament to the impact of the disease even at its early stages.

A strength of this study's methodology was its detailed comparison of patients' reporting and physicians' beliefs about the burden of specific symptoms. Several disconnects between survey responses across these 2 groups were observed. Feeling exhausted or fatigue/tiredness occurred commonly among patients with ADPKD, and feeling exhausted was reported as a highly burdensome symptom by both early- and late-stage patients. However, physicians believed feeling exhausted was less burdensome at early and late disease stages than patients reported. It is possible that physicians do not fully appreciate both the physical and emotional fatigue patients with ADPKD experience. Patients may also feel physicians do not take their reports of this symptom seriously and therefore stop reporting it, leading physicians to underestimate how frequently their patients actually experience fatigue. This underreporting may be particularly common in early disease stages, when patients have less frequent appointments with their nephrologists. The largest discrepancies between physicians' impressions and patients' reporting of symptom 


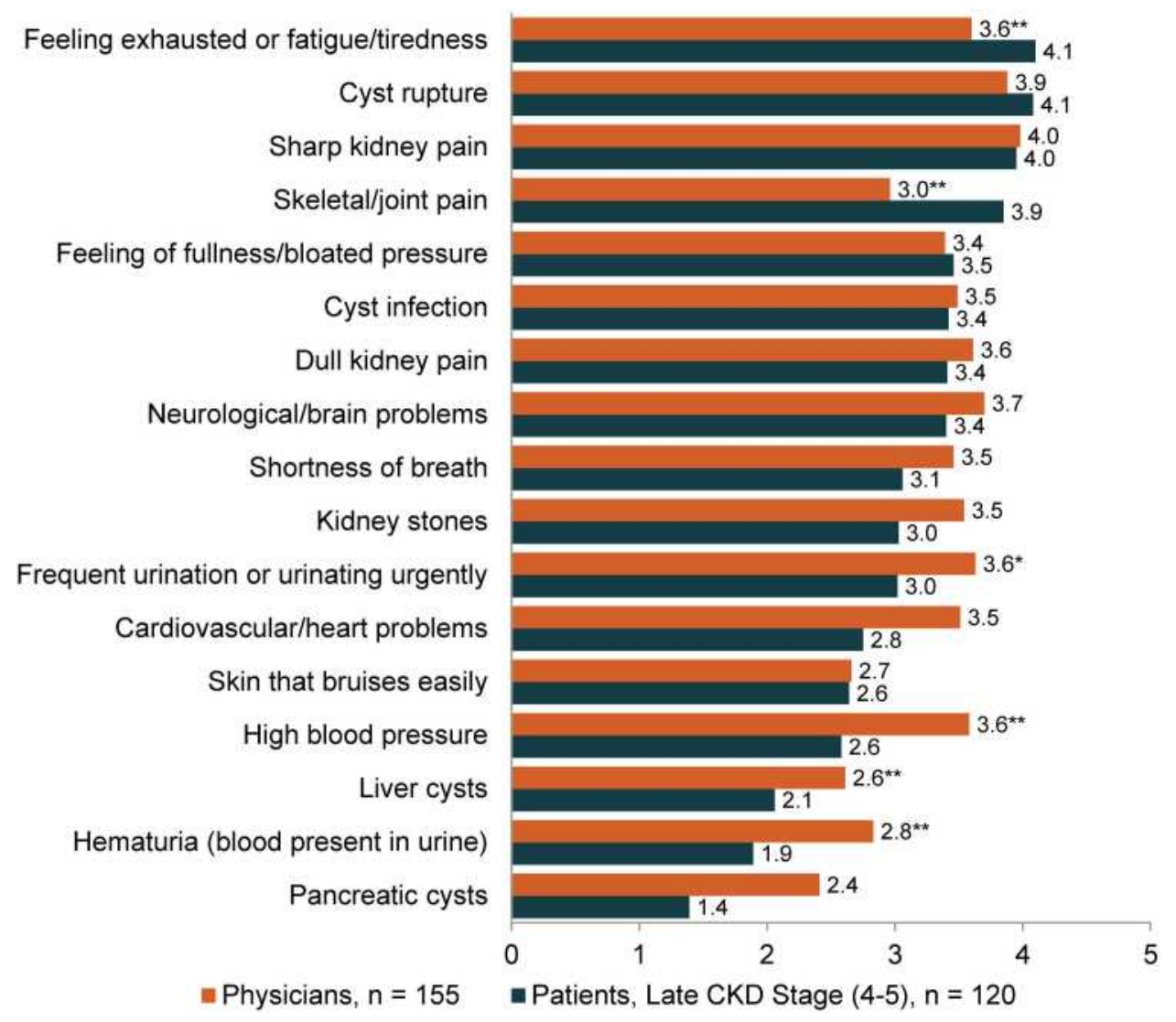

Figure 5 Late-stage (CKD stage 4-5) patients' versus physicians' assessments of symptom burden in ADPKD, ordered by patients' ratings of burden. Severity scale: I (least burdensome) to 5 (most burdensome). Only patients reporting they experienced a specific symptom rated the burden of that symptom. Of I55 physicians enrolled in the study, 147 remained after removing physicians with unknown/missing age and/or sex values. $P$ values were calculated using pairwise comparisons of age- and sex-adjusted estimated means. $* P<0.05, * * P<0.01$ versus patients.

Abbreviations: ADPKD, autosomal dominant polycystic kidney disease; CKD, chronic kidney disease.

burden occurred for patients with late-stage disease, who found skeletal/joint pain substantially more burdensome than physicians did.

In contrast, physicians viewed certain medical comorbidities, including hypertension, hematuria, and liver cysts, as more burdensome than patients did. Arguably, physicians may have a greater knowledge of the seriousness of these comorbidities and their potential long-term sequelae than some patients. Patients may have focused more on current burden than on long-term implications of specific comorbidities. It is also possible physicians focused more on the burden of symptoms and comorbidities that can be treated effectively, compared with those that cannot be (such as fatigue). Similarly, physicians may focus on disease manifestations they find most concerning and therefore place less emphasis on other symptoms (eg, skeletal) that patients find significant.

In previous studies, some patients with ADPKD reported feeling that physicians do not recognize the magnitude of their pain or take their pain seriously. ${ }^{16}$ Consistent with the findings of this study, earlier research found that most nephrologists and primary care physicians believed that patients with early-stage ADPKD experienced no or mild symptoms and no impact on daily activities. ${ }^{15}$ A similar underestimation by physicians of symptom burden relative to patients' experiences has been observed in other disease states. ${ }^{18,19}$

Our analysis encompassed a broad sample of patients at all stages of ADPKD. Similar to patients with ADPKD in a large US commercial and Medicare database, ${ }^{2}$ patients in this study were most often between 35 and 64 years old. The imbalance in patient sex in our sample, which was $69 \%$ female, is consistent with the earlier age of ADPKD diagnosis for women in the general population, possibly because of a greater use of ultrasound in women during child-bearing years (ie, during pregnancy). ${ }^{2}$ However, the proportion of our respondents who are women $(69 \%)$ is greater than the proportion of women in some US ADPKD 
patient populations $(\sim 52 \%){ }^{2}$ Because women with ADPKD generally have a greater burden of liver cysts and are more likely to experience urinary tract infections, ${ }^{4}$ any overrepresentation of women in this analysis may have affected study findings. Patients in this study also had generally high household incomes, education levels, and rates of insurance coverage, which may have influenced their experience of disease burden. For all of these reasons, our findings may not be generalizable to the full population of patients with ADPKD.

Limitations of this study include its cross-sectional design; findings should be considered associational rather than causal. Patients connected to the PKD Foundation and included in this study may be especially educated about and involved in the management of their condition and therefore may not be representative of all patients with ADPKD. Further, patients without e-mail and internet access were not included, which likely excluded a substantial proportion of patients with kidney disease. All data in this study were self-reported and thus may be prone to recall bias, misreporting, and selection bias. Our emphasis was on patients' experience of their symptom burden; a complete understanding of each patient's clinical presentation and the causes of their symptoms cannot be inferred from self-report. For example, for patients on dialysis, symptoms such as fatigue may have been related to treatment rather than the disease itself.

Nephrologists, particularly transplant nephrologists and those attached to academic centers (a large proportion of our physician sample), may be more accustomed to treating patients at late- versus early-stage ADPKD, which may have influenced our physician participants' perceptions of disease burden. Additionally, our physician participants had a mean caseload of 76.9 patients with ADPKD per year, a large number that may not be representative of all physicians treating ADPKD. CKD staging has limitations, and complications such as hypertension may track more closely with total kidney volume as a measure of disease severity. ${ }^{4,5}$ It is possible that physicians' responses would have differed if severity were based on kidney volume in this study. Although questions in this study regarding symptom burden and treatment were not part of a previously validated questionnaire, aspects of content validity were explored in cognitive interviews to ensure comprehension of survey items by patients and physicians.

The results of this study suggest a disconnect between patients' experiences and physicians' awareness of the burden of ADPKD, particularly during its early stages, and may highlight the need for more patient/physician discussion of current symptoms and disease management. The results also highlight the need for effective and early treatment to lessen the burden of ADPKD.

\section{Acknowledgments}

This paper was presented as a poster titled "Patient Voice in Autosomal Dominant Polycystic Kidney Disease (ADPKD): Findings from a Large Cross-sectional Survey in the United States" at the National Kidney Foundation 2019 Spring Clinical Meetings, which was held May 8-12, 2019, in Boston, Massachusetts. The abstract of this paper was published in Am J Kid Dis. 2019;73(4):728. https://www.ajkd. org/action/doSearch?text $1=$ Patient + Voice + in + Autosomal + Dominant $+\&$ field1 $=$ AllField. Editorial support for this article was provided by Lisa Baker, PhD, Melissa L. Bogen, ELS, and Esther Tazartes, MS, of the Global Outcomes Group. Editorial support was funded by Otsuka Pharmaceutical Development \& Commercialization, Princeton, NJ.

\section{Author Contributions}

All authors made a significant contribution to the work reported, whether that is in the conception, study design, execution, acquisition of data, analysis and interpretation, or in all these areas; took part in drafting, revising or critically reviewing the article; gave final approval of the version to be published; have agreed on the journal to which the article has been submitted; and agree to be accountable for all aspects of the work.

\section{Funding}

This research was supported by Otsuka Pharmaceutical Development \& Commercialization, Princeton, NJ.

\section{Disclosure}

Dorothee Oberdhan is an employee and Christina S. Pao and Myrlene Sanon Aigbogun were formerly employees of Otsuka Pharmaceutical Development \& Commercialization, Inc. Christina S. Pao is currently an employee of GSK, and Myrlene Sanon Aigbogun is currently an employee of The Janssen Pharmaceutical Companies of Johnson \& Johnson. Jillian Rooney and Brian Inyart are employees of Kantar, and Michael J. Doane was formerly an employee of Kantar. Alexis H. Denny was formerly an employee of the PKD Foundation and reports grants from Otsuka, outside the 
submitted work. The authors report no other conflicts of interest in this work.

\section{References}

1. PKD Foundation. What is ADPKD? 2019. Available from: https:// pkdcure.org/what-is-pkd/adpkd/. Accessed August 29, 2019.

2. Willey C, Kamat S, Stellhorn R, Blais J. Analysis of nationwide data to determine the incidence and diagnosed prevalence of autosomal dominant polycystic kidney disease in the USA: 2013-2015. Kidney Dis (Basel). 2019;5(2):107-117. doi:10.1159/000494923

3. Willey CJ, Blais JD, Hall AK, Krasa HB, Makin AJ, Czerwiec FS. Prevalence of autosomal dominant polycystic kidney disease in the European Union. Nephrol Dial Transplant. 2017;32(8):1356-1363. doi:10.1093/ndt/gfw240

4. Chebib FT, Torres VE. Autosomal dominant polycystic kidney disease: core curriculum 2016. Am J Kidney Dis. 2016;67(5):792-810. doi:10.1053/j.ajkd.2015.07.037

5. Grantham JJ, Torres VE, Chapman AB, et al. Volume progression in polycystic kidney disease. $N$ Engl J Med. 2006;354(20):2122-2130. doi:10.1056/NEJMoa054341

6. Torres VE, Harris PC. Autosomal dominant polycystic kidney disease: the last 3 years. Kidney Int. 2009;76(2):149-168. doi:10.1038/ ki.2009.128

7. Miskulin DC, Abebe KZ, Chapman AB, et al. Health-related quality of life in patients with autosomal dominant polycystic kidney disease and CKD stages 1-4: a cross-sectional study. Am J Kidney Dis. 2014;63(2):214-226. doi:10.1053/j.ajkd.2013.08.017

8. National Kidney Foundation. What are the stages of chronic kidney disease? 2019. Available from: https://www.kidney.org/blog/kidney-cars /what-are-stages-chronic-kidney-disease. Accessed August 30, 2019.

9. Kidney Disease: Improving Global Outcomes (KDIGO) CKD Work Group. KDIGO 2012 Clinical Practice Guideline for the Evaluation and Management of Chronic Kidney Disease. Kidney Int Suppl. 2013;3:1-150.

10. Suwabe T, Ubara Y, Mise K, et al. Quality of life of patients with ADPKD-Toranomon PKD QOL study: cross-sectional study. $B M C$ Nephrol. 2013;14(1):179. doi:10.1186/1471-2369-14-179
11. Barnawi RA, Attar RZ, Alfaer SS, Safdar OY. Is the light at the end of the tunnel nigh? A review of ADPKD focusing on the burden of disease and tolvaptan as a new treatment. Int $J$ Nephrol Renovasc Dis. 2018;11:53-67. doi:10.2147/IJNRD.S136359

12. Oberdhan D, Cole JC, Krasa HB, et al. Development of the Autosomal Dominant Polycystic Kidney Disease Impact Scale: a new health-related quality-of-life instrument. Am J Kidney Dis. 2018;71(2):225-235. doi:10.1053/j.ajkd.2017.08.020

13. Eriksson D, Karlsson L, Eklund O, et al. Health-related quality of life across all stages of autosomal dominant polycystic kidney disease. Nephrol Dial Transplant. 2017;32(12):2106-2111. doi:10.1093/ndt/ gfw335

14. Simms RJ, Thong KM, Dworschak GC, Ong AC. Increased psychosocial risk, depression and reduced quality of life living with autosomal dominant polycystic kidney disease. Nephrol Dial Transplant. 2016;31(7):1130-1140. doi:10.1093/ndt/gfv299

15. Baker A, King D, Marsh J, et al. Understanding the physical and emotional impact of early-stage ADPKD: experiences and perspectives of patients and physicians. Clin Kidney J. 2015;8(5):531-537. doi:10.1093/ckj/sfv060

16. Tong A, Rangan GK, Ruospo M, et al. A painful inheritance-patient perspectives on living with polycystic kidney disease: thematic synthesis of qualitative research. Nephrol Dial Transplant. 2015;30 (5):790-800. doi:10.1093/ndt/gfv010

17. Reilly Associates. WPAI general information; 2019. Available from: http://www.reillyassociates.net/WPAI_General.html. Accessed August 29, 2019.

18. Mesa RA, Miller CB, Thyne M, et al. Differences in treatment goals and perception of symptom burden between patients with myeloproliferative neoplasms (MPNs) and hematologists/oncologists in the United States: findings from the MPN Landmark survey. Cancer. 2017;123(3):449-458. doi:10.1002/cncr.30325

19. Wilcox AR, Dragnev MC, Darcey CJ, Siegel CA. A new tool to measure the burden of Crohn's disease and its treatment: do patient and physician perceptions match? Inflamm Bowel Dis. 2010;16 (4):645-650. doi:10.1002/ibd.21094
The International Journal of Nephrology and Renovascular Disease is an international, peer-reviewed open-access journal focusing on the pathophysiology of the kidney and vascular supply. Epidemiology, screening, diagnosis, and treatment interventions are covered as well as basic science, biochemical and immunological studies. The manuscript management system is completely online and includes a very quick and fair peer-review system, which is all easy to use. Visit http://www.dovepress.com/testimonials.php to read real quotes from published authors. 